Article

\title{
A New Friedelane Type Triterpene from Euonymus hederaceus
}

Cui-Rong Sun ${ }^{1, *}$, He-Jiao Hu ${ }^{1}$, Run-Sheng Xu ${ }^{1}$, Jie-Hong Yang ${ }^{2}$ and Hai-Tong Wan ${ }^{2, *}$

1 Department of Chemistry, Zhejiang University, Hangzhou 310027, China

2 Institute of Cardio-Cerbrovascular Disease, Zhejiang Chinese Medical University, Hangzhou 310053, China; E-mail: yangjiehong@zjtcm.net (J-H.Y.)

* Authors to whom correspondence should be addressed; E-mails: suncuirong@zju.edu.cn (C-R.S.), wanhaitong@zjtcm.net (H-T.W.)

Received: 22 June 2009; in revised form: 10 July 2009 / Accepted: 15 July 2009 /

Published: 17 July 2009

\begin{abstract}
Euonymus hederaceus is distributed widely in the south of China; its stems and leaves have been used as folk medicines to treat many diseases such as renal deficiency and chronic diarrhea, traumatic injury, and abnormal menstruation. Chemical investigation of the leaves and stems of Euonymus hederaceus resulted in the isolation for the first time and characterization of a new friedelane type triterpene with a molecular mass of 472 and molecular formula of $\mathrm{C}_{30} \mathrm{H}_{48} \mathrm{O}_{4}$ by high resolution mass spectrometry. The ${ }^{1} \mathrm{H}-\mathrm{NMR}$ ${ }^{13} \mathrm{C}$-NMR and DEPT $135^{\circ}$ spectra matched the characteristic data of the proposed triterpene skeleton. The compound was finally identified as 28-hydroxyfriedelan-3-one-29-oic acid on the basis of spectroscopic evidence, including two dimensional nuclear magnetic resonance as well as its IR spectrum.
\end{abstract}

Keywords: Euonymus hederaceus; new friedelane triterpene; 28-hydroxyfriedelan3-one-29-oic acid; structure elucidation

\section{Introduction}

Celastraceae plants have been the subject of continued and growing interest due to the range of biological activities shown by many members of this family. Pharmaceutical studies and clinical practice have demonstrated that their sesquiterpenes and triterpenes possess notable antibacterial, anti-tumor, insect antifeedant and cytotoxic activities. More than 100 compounds have been isolated 
and purified from three species, including Celastrus hypoleucus (Oliv.) Warb [1], Celastrus hypoleucus [2], and Microtropis triflora Merr [3] belonging to the Celastraceae family. The structures were determined by IR, UV, MS, and NMR, respectively, and 13 of them were new compounds. Friedelin ring triterpenes are a very important class, and so far, these compounds were reported to display a lot of biological activity. For example, 28,30-dihydroxyfriedelan-3-one showed good anti-tumor activity against P388 [4].

Euonymus hederaceus (Celastraceae) is a scramble shrub cultivated as an ornamental or hedge plant and widely distributed in Anhui, Jiangsu, Zhejiang, Jiangxi, Fujian, Hunan, Guangdong, and Guangxi provinces in China and Taiwan. Its decoctions are reputed in traditional medicine for their antibiotic and anti-tumor properties [5]. Euonymus hederaceus was investigated for the first time in our group, and five known friedelane triterpenes: 3-friedelone, 28-hydroxyfriedelan-3-one (canophyllal), 28-hydroxy-3-friedelanone (canophyllol), 30-hydroxy-3-friedelanone, 29-hydroxy-3-friedelanone and three olean-type triterpenoids including 3 $\beta$-methoxyolean-11-oxo-18-ene, olean-12-ene-3,11-dione and 28-hydroxyolean-12-ene-3,11-dione were separated and their structures elucidated [6]. We report here the isolation and structure elucidation of a new triterpene by a combination of NMR techniques, including ${ }^{1} \mathrm{H}-\mathrm{NMR},{ }^{13} \mathrm{C}-\mathrm{NMR}$, DEPT $135^{0},{ }^{1} \mathrm{H}-{ }^{1} \mathrm{HCOSY}$, HMQC and HMBC.

\section{Results and Discussion}

Compound 1: acicular crystals, m.p. $294-296{ }^{\circ} \mathrm{C},[\alpha]_{\mathrm{D}}^{20}:-8.016(\mathrm{MeOH})$. Its molecular formula was deduced to be $\mathrm{C}_{30} \mathrm{H}_{48} \mathrm{O}_{4}$ (ESI-MS $m / z$ : $473.3629[\mathrm{M}+\mathrm{H}]^{+}$, calcd. 473.3625). The IR spectrum showed absorptions at $v_{\max } 3,426,1,718$ and $1,707 \mathrm{~cm}^{-1}$, compatible with the presence of hydroxyl $(\mathrm{OH})$ and two carbonyl functionalities, respectively. The ${ }^{1} \mathrm{H}-\mathrm{NMR}\left(\mathrm{C}_{5} \mathrm{D}_{5} \mathrm{~N}\right)$ spectra exhibited 46 protons, while the ${ }^{13} \mathrm{C}$-NMR and DEPT $135^{\circ}$ spectra showed a total of 30 carbon signals: six primary carbons, twelve secondary carbons, four tertiary carbons and eight quaternary carbons, which were consistent with the characteristic of triterpene skeleton. Six methyl group signals at $\delta 0.66,0.79,1.04,1.44,1.45$ (s, $3 \mathrm{H}$ each) and $0.95(\mathrm{~d}, 3 \mathrm{H})$ were observed in the ${ }^{1} \mathrm{H}-\mathrm{NMR}$ spectrum, in combination with six carbon signals at $\delta 14.6,18.5,15.7,18.7,33.0$, and 7.2 (Table 1) in the ${ }^{13} \mathrm{C}-\mathrm{NMR}$ spectrum, which exhibited one methyl less than that of 28-hydroxy-friedelan-3-one. The HMBC correlations (Table 1) for the signals H-2 $(\delta 2.20), \mathrm{H}-23(\delta$ 0.95), and H-4 $(\delta 2.12)$ with carbonyl carbon at $\delta 211.8$ and for the signals H-28 $(\delta 3.89,3.94)$ with $\mathrm{C} 16, \mathrm{C} 22$, and $\mathrm{C} 18$ were consistent with a 28-hydroxy-3-one type friedelane triterpene. Long-range correlations (HMBC) observed for the signals H-19 $(\delta 1.60), \mathrm{H}-30(\delta$ $1.45)$, and $\mathrm{H}-21(\delta$ 1.77) with carbonyl carbon at $\delta 181.0$ suggested the presence of another carbonyl group at $\mathrm{C} 29$, in agreement with the absorption at $v_{\max } 1,707 \mathrm{~cm}^{-1}$ revealed by the IR spectrum. Comparing with the carbon spectrum with those of 28-hydroxy-friedelan-3-one (Figure 1) and 2-hydroxy-3-oxo-friedelan-29-oic acid [7-8] as well as 2D data (Table 1), differences were also observed: specifically a downfield shift at $\mathrm{C} 20$ ( $\delta$ 40.8, for compound $\mathbf{1} ; \delta$ 28.1, for 28-hydroxy-friedelan-3-one) and $\mathrm{C} 29$ ( $\delta$ 181.0, for compound $\mathbf{1} ; \delta 32.9$, for 28-hydroxyfriedelan-3-one). Therefore, compound 1 was identified as 28-hydroxyfriedelan-3-one-29-oic acid (Figure 2). 
Figure 1. The structure of 28-hydroxy-friedelan-3-one.

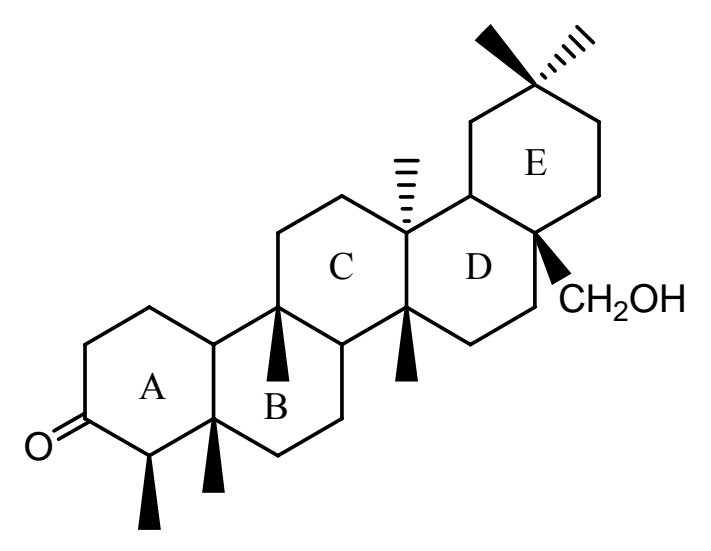

Figure 2. The structure of compound 1.

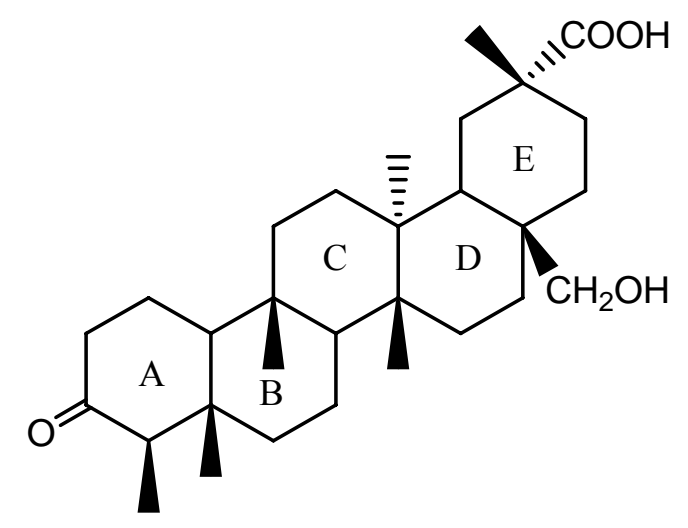

As reported, the D and E-rings adopted boat-boat conformation for 3-friedelin, because the repulsion between C29 and C27 is very strong [9]. However, when C29 was oxidized to a carboxylic acid or aldehyde, the D and E-ring would favor chair-chair conformation due to release of the repulsion [4,10]. So it was speculated that rings $\mathrm{D} / \mathrm{E}$ in compound $\mathbf{1}$ adopted a chair-chair conformation (Figure 3 ).

Figure 3. The chair-chair conformation of compound $\mathbf{1}$.

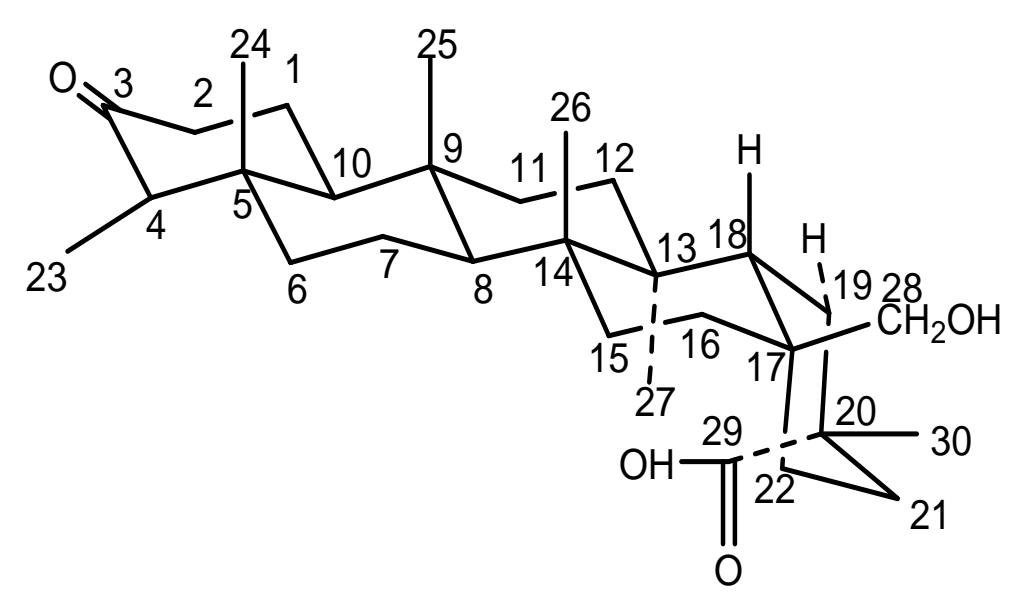


Table 1. 1D NMR and 2D NMR data for compound 1.

\begin{tabular}{|c|c|c|c|c|c|}
\hline \multirow[b]{2}{*}{ Position } & \multicolumn{3}{|c|}{$\delta_{C}$} & \multicolumn{2}{|c|}{ Compound 1} \\
\hline & $\begin{array}{l}\text { Compound } \\
\mathbf{1} \text { in } \\
\text { pyridine- } \mathrm{D}_{5}\end{array}$ & $\begin{array}{c}\text { 28-hydroxy- } \\
\text { friedelan-3- } \\
\text { one }\end{array}$ & $\begin{array}{l}\text { 2-hydroxy-3- } \\
\text { oxo-friedelan } \\
\text {-29-oic acid }\end{array}$ & $\operatorname{HMQC~}\left(\delta_{H}\right)$ & HMBC \\
\hline $\mathrm{C} 1$ & 22.4 & 22.3 & 32.5 & $\begin{array}{l}1.50(\mathrm{~m}), \\
1.73(\mathrm{~m})\end{array}$ & / \\
\hline $\mathrm{C} 2$ & 41.5 & 41.5 & 75.0 & $\begin{array}{c}2.20(\mathrm{~m}), 2.38 \\
(\mathrm{~m})\end{array}$ & / \\
\hline $\mathrm{C} 3$ & 211.8 & 212.6 & 212.4 & / & H-2,4,24 \\
\hline $\mathrm{C} 4$ & 57.8 & 58.1 & 55.6 & $2.12(\mathrm{q}, \mathrm{J}=6.8)$ & H-23,24 \\
\hline $\mathrm{C} 5$ & 41.9 & 42.1 & 43.0 & / & H-4, 10,23,24 \\
\hline C6 & 41.1 & 41.2 & 41.2 & $\begin{array}{c}1.10(\mathrm{~m}), 1.54 \\
(\mathrm{~m})\end{array}$ & H-24 \\
\hline $\mathrm{C} 7$ & 18.4 & 18.2 & 18.2 & $1.23(\mathrm{~m})$ & H-8 \\
\hline $\mathrm{C} 8$ & 50.4 & 52.4 & 50.8 & $1.39(\mathrm{~m})$ & H-25,26 \\
\hline C9 & 37.6 & 37.4 & 37.4 & I & H-8, 10,25 \\
\hline $\mathrm{C} 10$ & 59.2 & 59.4 & 56.8 & $1.40(\mathrm{~m})$ & H-24,25 \\
\hline $\mathrm{C} 11$ & 35.5 & 35.4 & 35.3 & $1.30(\mathrm{~m})$ & H-25 \\
\hline $\mathrm{C} 12$ & 29.7 & 30.1 & 29.5 & $1.80(\mathrm{~m})$ & H-27 \\
\hline $\mathrm{C} 13$ & 39.5 & 39.3 & 39.3 & I & $\begin{array}{c}\mathrm{H}-11,12,18 \\
\mathrm{H}-27\end{array}$ \\
\hline $\mathrm{C} 14$ & 39.4 & 38.1 & 39.3 & I & $\begin{array}{c}\mathrm{H}-7,12,18,26 \\
\mathrm{H}-27\end{array}$ \\
\hline $\mathrm{C} 15$ & 29.1 & 31.2 & 29.4 & $1.41(\mathrm{~m})$ & H-26 \\
\hline $\mathrm{C} 16$ & 31.4 & 29.1 & 36.1 & $\begin{array}{c}1.52(\mathrm{~m}), 2.44 \\
(\mathrm{~m})\end{array}$ & H-28 \\
\hline $\mathrm{C} 17$ & 35.6 & 35.1 & 30.1 & / & $\mathrm{H}-18$ \\
\hline $\mathrm{C} 18$ & 40.3 & 39.4 & 44.2 & $1.89(\mathrm{~m})$ & H-28 \\
\hline C19 & 30.3 & 34.5 & 30.3 & $\begin{array}{c}1.60(\mathrm{~m}), 2.62 \\
(\mathrm{~m})\end{array}$ & $\mathrm{H}-30$ \\
\hline $\mathrm{C} 20$ & 40.8 & 28.1 & 40.4 & 1 & H-18,22,30 \\
\hline $\mathrm{C} 21$ & 31.1 & 31.4 & 29.7 & $\begin{array}{c}1.77(\mathrm{~m}), 2.82 \\
(\mathrm{~m})\end{array}$ & I \\
\hline $\mathrm{C} 22$ & 32.1 & 33.3 & 36.7 & $\begin{array}{c}2.44(\mathrm{~m}), 1.79 \\
(\mathrm{~m})\end{array}$ & H-28 \\
\hline $\mathrm{C} 23$ & 7.2 & 6.8 & 6.6 & $0.95(\mathrm{~d}, \mathrm{~J} 6.8)$ & $\mathrm{H}-4,5$ \\
\hline $\mathrm{C} 24$ & 14.6 & 14.7 & 14.7 & $0.66(\mathrm{~s})$ & $\mathrm{H}-4$ \\
\hline $\mathrm{C} 25$ & 18.5 & 18.1 & 18.5 & $0.79(\mathrm{~s})$ & $\mathrm{H}-8,10$ \\
\hline $\mathrm{C} 26$ & 15.7 & 19.2 & 16.4 & $1.04(\mathrm{~s})$ & I \\
\hline $\mathrm{C} 27$ & 18.7 & 19.1 & 18.1 & $1.44(\mathrm{~s})$ & H-18 \\
\hline $\mathrm{C} 28$ & 69.4 & 70.0 & 31.9 & $\begin{array}{c}3.89,3.93(\mathrm{dd} \\
\mathrm{J} 10.4)\end{array}$ & H-18 \\
\hline $\mathrm{C} 29$ & 181.0 & 32.9 & 184.4 & / & H-19,21,30 \\
\hline $\mathrm{C} 30$ & 33.0 & 34.3 & 31.4 & $1.45(\mathrm{~s})$ & H-21 \\
\hline
\end{tabular}




\section{Experimental}

\section{General}

The IR spectrum was recorded in KBr pellets on a Nicolet NEXUS-470 FT-IR spectrometer. NMR spectra were recorded on a Bruker Avance DMX 500 NMR Instrument (Bruker Analytik, GmbH, Germany). The chemical shift values are given in ppm using pyridine- $\mathrm{D}_{5}$ as solvent and TMS as the internal standard. Mass spectra were performed on an Apex III (7.0 Tesla) Fourier transformation ion cyclotron resonance mass spectrometer (FT-ICRMS) equipped with electrospray ionization source (ESI) (Bruker, Billerica, MA, USA).

\section{Plant material}

The whole plant of Euonymus hederaceus was collected in Jiulong Mountain, Suichang County, Zhejiang Province, P. R. China in October 2003, and identified by Dr. Haitong Wan (Zhejiang Chinese Medical University, Hangzhou, P. R. China.). A voucher specimen was deposited in the College of Agriculture and Biotechnology, Zhejiang University, Hangzhou, P. R. China.

\section{Extraction and isolation}

The shade-dried, powdered root barks, stem barks and leaves of Euonymus hederaceus $(5.0 \mathrm{~kg})$ were extracted three times with $95 \% \mathrm{EtOH}(20 \mathrm{~L})$ at room temperature for seven days. After removal of the solvent in vacuo, the extract was dissolved in $\mathrm{H}_{2} \mathrm{O}(0.5 \mathrm{~L})$ and extracted with EtOAc $(2 \mathrm{~L})$. The concentrated EtOAc extract ( $75 \mathrm{~g}$ ) was subjected to column chromatography (CC) on silica gel, eluting with petroleum ether and increasing proportions of EtOAc. The eluate with 1:9 (petroleum ether/EtOAc) give the new pure compound 1 (10 mg).

\section{Conclusions}

A new friedelane type triterpene was isolated from Euonymus hederaceus, its structure was determined to be 28-hydroxy-friedelan-3-one-29-oic acid by spectroscopic methods, including FT-ICRMS and NMR experiments, in combination to the comparison with known compounds. In addition, its stereo structure was proposed on the basis of the reference data.

\section{Acknowledgments}

The authors gratefully acknowledge financial support from the National Natural Science Foundation of China (No: 20772109) and Zhejiang Provincial Program for the Cultivation of High-level Innovative Health Talent Fellowship. 


\section{References and Notes}

1. Wang, K.W.; Sun, H.X.; Wu, B.; Pan, Y.J. Two Novel Olean Triterpenoids from Celastrus hypoleucus. Helv. Chim. Acta 2005, 88, 990-995.

2. Wang, K.W.; Mao, J.S.; Tai, Y.P.; Pan, Y.J. Novel skeleton terpenes from Celastrus hypoleucus with anti-tumor activities. Bioorg. Med. Chem. Lett. 2006, 16, 2274-2277.

3. Wang, K.W.; Zhang, H.; Pan, Y.J. Novel Triterpenoids from Microtropis triflora with Antitumor Activities. Helv. Chim. Acta 2007, 90, 277-281.

4. Nozaki, H.; Suzuki, H.; Lee, K.; Mephail, A. Structure and stereochemistry of maytenfolic acid and maytenfoliol, two new antileukemic triterpenes from Maytenus diversifolia: X-ray crystal structures. J. Chem. Soc. 1982, 18, 1048-1051.

5. Chang, Z.F.; Lu, G.P.; Wei, J.; Song, F.X. Chinese medicinal plant Celastraceae properties preliminary processing. Chin. J. Inf. Trad. Chin. Med. 1996, 3, 29-32.

6. Ren W.L.; Hu, H.J.; Pan, Y.J. Studies on olean-type triterpenoids of Euonymus hederaceus. J. Zhejiang Univ. (Science Edition). 2006, 33, 196-199.

7. Hongquan, D.; Yoshihisa, T.; Hiroshi, M.; Yasukazu, O.; Takao, T.; Jia, Y.; Li, D. Triterpenoids from Tripterygium wilford II. Phytochemistry 2000, 53, 805-810.

8. Patra, A.; Chaudhuri, S.K.; Rübgger, H. Complete ${ }^{13} \mathrm{C}$ and ${ }^{1} \mathrm{H}$ spectral assignments of friedelin by inadequate and heteronuclear $\left({ }^{13} \mathrm{C}-{ }^{1} \mathrm{H}\right)$ correlation experiments. J. Indian Chem. Soc. 1990, 67, 394-397.

9. Mariano, M.V.; Miguel, M.C.; Cristina, S.V.; Lydia, R.H.; Pedro, J.N. Terpenoids from Mortonia diffusa. J. Nat. Prod. 1988, 51, 793-796.

10. Gottlieb, H.E.; Ramaiah, P.; Lavie, A.D. ${ }^{13} \mathrm{C}$ NMR signal assignment of friedelin and 3-hydroxyfriedelan-2-one. Magn. Reson. Chem. 1985, 23, 616-619.

Sample Availability: Samples of compound $\mathbf{1}$ are available from the authors.

(C) 2009 by the authors; licensee Molecular Diversity Preservation International, Basel, Switzerland. This article is an open-access article distributed under the terms and conditions of the Creative Commons Attribution license (http://creativecommons.org/licenses/by/3.0/). 